\title{
Selection among the systematists
}

\author{
Philip Kitcher
}

Science as a Process: An Evolutionary Account of the Social and Conceptual Development of Science. By David L. Hull. University of Chicago Press: 1988. Pp. 586. \$39.95. To be published in Britain in December, £31.95.

AcCording to Legend, the white coats that scientists wear are emblematic, for scientists are surely the good guys, serious, humble, scrupulously honest and dedicated to sacrificing themselves in the pursuit of Knowledge. Legend has not gone unchallenged in the two decades since James Watson offered his famous account of the race to find the structure of DNA, but it lives on in journalistic reports of scientific practice, in the reflections of many scientists, and in the descriptions offered by many historians and philosophers of science. David Hull believes that it is time to take a closer look. His fascinating book attempts to portray the factors that are really at work in the process of science, to present one case in detail and to put forward a general theory.

Using the vocabulary of Legend, we might divide the book naturally into two parts: data and hypotheses. For his data, Hull has gone primarily to the community (or, more exactly, communities) of systematists whose doings he has followed closely for about 15 years. He offers a vivid chronicle of the formation of research groups, of coalitions and alliances, of collaboration and confrontation. The drama often runs high. Friendships (even marriages) are made, hostility and jealousy thrive, and, from time to time, the heroes plot revenge against those who have tried to thwart their ambitions. Yet, like any good primatologist, Hull has great sympathy for his subjects. They emerge from his narrative without white coats, not always admirable, but thoroughly human.

Hull advances hypotheses at two levels. In the early chapters he uses the data to support claims about the kinds of motives that are prominent in the daily practice of science. This sociological theorizing is to be embedded in a more general analysis, advanced in the second half of the book, in which science is viewed as a selection process. In any generation of science, ideas are spawned in profusion. Some of these ideas, perhaps because of their own intrinsic merits, perhaps because of the activities of the scientists who promulgate them, are more likely to be replicated than others. While the less fortunate vanish without trace, the successful ones find their ways into the brains of many scientists, perhaps even securing the status of textbook embodiment. Scientists themselves are active in the war of ideas, for each is driven not only by curiosity (which Hull recognizes as an important part of scientific motivation) but also by the desire to secure credit. So we are offered the picture of a community of investigators who sometimes cooperate and who offer one another recognition for their contributions, but who compete for the flourishing of their own intellectual property. Success comes in having your ideas widely used and properly attributed to you.

"Legend-bashers typically attract science-bashers, and Hull can expect some of his readers to conclude that he has revealed science as brutal warfare among ambitious egoists, a process that has nothing to do with rational argument or the uncovering of truth."

Objections to evolutionary accounts of human knowledge (and to darwinian accounts in particular) are familiar, and Hull attempts to defuse them by offering a very abstract analysis of selection processes. The core of his idea, familiar from his earlier writings, is that there are two important kinds of entities, replicators and interactors. Replicators are things that have the power to transmit their structure with reasonably high fidelity. Interactors cause differential replication of replicators by their interaction with some environment. Selection occurs when variation in the success of interactors causes the differential perpetuation of associated replicators. Starting from this general proposal, Hull surveys the variety of ways in which the natural selection of organisms occurs and tries to show that worries about applying selectionist ideas to the dynamics of knowledge are unfounded.

Presented with a gripping tale of science in the raw, some sociological generalizations about spurs to research and an abstract account of the workings of selection, it is natural to ask a number of questions. How typical is the case that Hull describes? How well does the case exemplify the general theory? How different is the perspective provided by the theory from that offered us by Legend? For all its many virtues, Science as a Process fails to resolve the doubts that lurk behind these questions.

Hull is sensitive to the charge that his quarrelsome systematists are atypical. $\mathrm{He}$ responds by alluding to other historical and sociological studies and by denying the legitimacy of asking for the behaviour of the 'typical scientist'. In my judgement, these responses do not take full account of the force of the objection. Many social practices, including the academic disciplines of philosophy and literary criticism, would have served equally well to illustrate the power of the motives that Hull lays bare - philosophers, in particular, are a notoriously argumentative lot. Yet journalists rarely celebrate the progress of philosophy. If philosophy and science are subserved by the same mechanisms, what accounts for the difference in their apparent results?

That question is bound to loom large when one looks more closely at the issues in dispute between Hull's warring systematists. Those issues concern the 'philosophy' of taxonomy, the 'first principles' on which a 'proper' systematics should be based. The Legend-lover now understands why the behaviour Hull records was to be expected: of course, when scientists wander off into philosophical speculation there will be no objective standards to guide them and they will lose themselves in sterile wrangling.

Even if we set on one side concerns about the representativeness of the scientists whom Hull has studied, the relation of data to hypotheses still proves troublesome. Although Hull's chronicle is keyed to his sociological generalizations, it is simply not clear what aspects of the behaviour of the systematists are illuminated by the very general account of the selection process that he gives in the second half of the book. In part, this is a consequence of the lack of detail: Hull has very little to say about the processes through which scientific ideas are replicated or what makes them successful in the struggle for replication. But, in his defence, we could note that Darwin was forced to complain that his own ignorance about the processes of variation and inheritance was "profound". Perhaps we can then excuse the absence of detail in Hull's account, trusting that the specifics can be filled out later. Indeed but in the interim we need a reason to think that a selectionist theory of the growth of science will do some explanatory work. Darwin succeeded, despite his professed ignorance, because he could fill the Origin with descriptions of phenomena that could be understood on the basis of common descent or of natural selection and which were otherwise inexplicable. Science as a Process contains nothing like that.

One facet of science that Hull regards as needing explanation is the fact that failure to acknowledge the ideas of another scientist is typically regarded as less serious than scientific fraud. His explanation turns on the idea that the theft of an idea only harms one person, while the 
publication of fraudulent data can disrupt the research of many. Even if this is correct - and one of the obvious rival explanations is that judgements about failure to assign credit are often tempered by the suspicion that the borrowing was inadvertent - it is far from clear that Hull's evolutionary account has any role to play in articulating the explanation. The lacuna here points to an important flaw in the book. There are some interesting findings about the behaviour of a group of scientists and a very abstract account of the metaphysics of selection. The wheels, however, never quite mesh.

Legend-bashers typically attract science-bashers, and Hull can expect some of his readers to conclude that he has revealed science as brutal warfare among ambitious egoists, a process that has nothing to do with rational argument or the uncovering of truth. Yet the author himself has no truck with fashionable relativisms. He is confident that science makes progress, and that, as a way of attaining knowledge of the world "it beats all other ways hollow" (p.26). Indeed, at his most venturesome, Hull promises to show that science advances because of the polemics, the keen desire for revenge, the intellectual competitiveness, all the marks of the behaviour of his subjects that make defenders of Legend avert their eyes in horror. The promise envisages a thoroughly naturalistic approach to science in which it is shown how certain kinds of intellectual and social forces contribute to the attainment of epistemic goals. But Hull's book does not deliver. Nor could it, for it treats the transmission and origination of scientific ideas at far too abstract and imprecise a level, and it is selfconsciously silent on some of the epistemological questions that any successful development of the naturalistic project should address.

Legend is overdue for replacement, and an adequate replacement must attend to the process of science as carefully as Hull has done. I share his vision of a serious account of the social and intellectual dynamics of science that will avoid both the rosy blur of Legend and the facile charms of relativism. The faults of his book are those of omission, but it is only fair to recognize that they are dwarfed by the accomplishments. Because of the author's deep concern with the ways in which research is actually done, Science as a Process begins an important project in the study of science. It is one of a distinguished series of books, which Hull himself edits, and which in recent years has greatly advanced the history, philosophy and sociology of science. The editor should be more than happy with the author's contribution.

Philip Kitcher is a Professor in the Department of Philosophy, University of California, San Diego, La Jolla, California 92093, USA.

\section{The better way to better health}

Stephen Lock

The Origins of Human Disease. By Thomas McKeown. Basil Blackwell:1988. Pp.233. $£ 22.50, \$ 34.95$.

UNDERPINNING today's craze for jogging and bran is a formidable amount of epidemiology, here cogently summarized in the late Thomas McKeown's last book. Uniting his principal interests in the history of populations and of infections with a forensic power of argument, McKeown concludes that three influences on health stand out: infection, malnutrition and population growth. Medical advances have played only a minor part in improving things, a conclusion that will hardly endear him to the medical establishment any more than did his earlier, similar claims. Nor will politicians welcome his emphasis that we already have much of the knowledge needed to improve health rapidly; what is lacking is effective management and a political commitment to equality of opportunities for good health. But McKeown is equal to any adversary and the blurb is accurate in describing his book as a tour de force.

Recent attacks on health care have been on different grounds: the economic incompetence of its delivery. But only a decade ago (when McKeown came on the scene) the intellectual wrangling was about the role of modern medicine, with allegations that it was positively deleterious to people's general well being. To be sure, medicine has seen off some powerful critics before - Voltaire and Bernard Shaw among them - and in the late 1970 s and early 1980 s it had little difficulty in coping with two of the new ones, Ivan Illich, an "intellectual Tyl Eulenspiegel", as the New England Journal of Medicine described him, was opposed to any aspect of industrialized society, and his appeal to restore pain and suffering to the individual evoked little enthusiasm. Ian Kennedy, the 1980 Reith lecturer, argued with a lawyer's subtlety but his lectures were condemned for their superficiality, particularly his accusation that doctors had usurped control of ethical decisions.

Both Illich and Kennedy provoked a useful debate about what part medicine played in health. Nevertheless, intellectual rigour was added when McKeown joined in, because he had both the appropriate knowledge and the debating skills. A Canadian Rhodes scholar, he had held academic appointments in the basic sciences before going to Birmingham and becoming a foundation professor of social medicine at the age of 32 . At Birmingham he created virtually a new subject, which came to concentrate on the changes in human populations and disease patterns. In some quarters his 1976 Rock Carling lecture on the role of medicine was interpreted as an attack on clinical care, and in a second edition, admitting that he had underestimated its value, he devoted

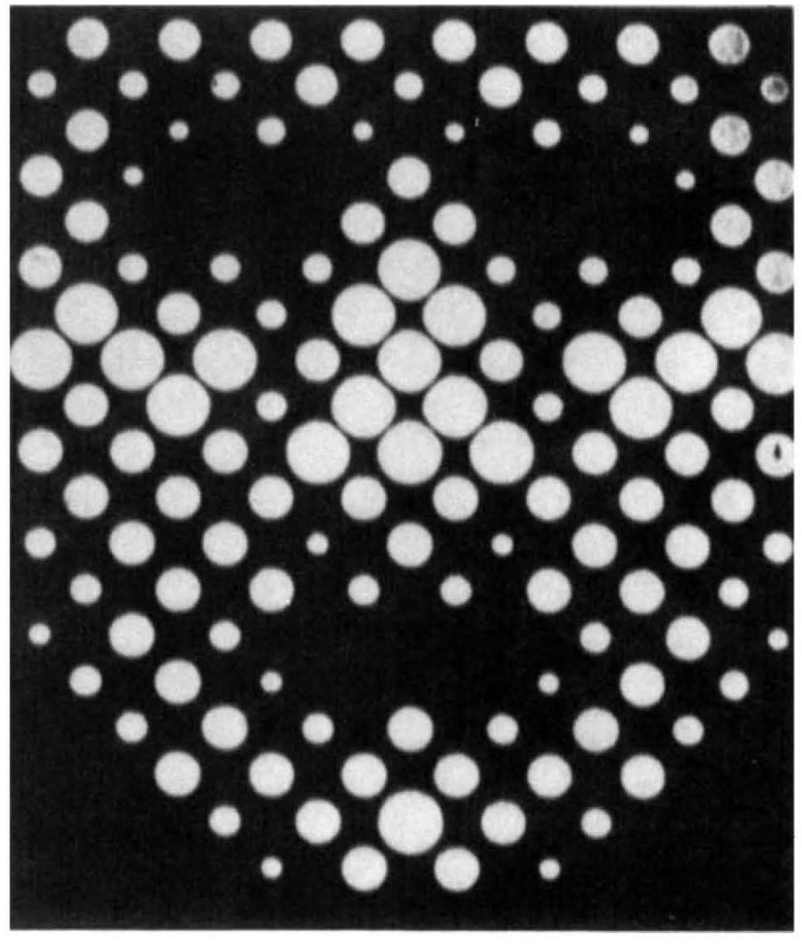

Arresting image -- the World Health Organization's multilanguage poster, produced in 1978 , announcing a $\$ 1,000$ reward for the first person reporting a confirmed case of smallpox acquired by person-to-person transmission. The reward remained valid until the global eradication of smallpox was certified in December 1979. The picture is taken from The Smallpox Story in Words and Pictures, by Abbas $M$. Behbehani, published by the University of Kansas Medical Center. price $\$ 15.95$ (North America), \$16.95 (elsewhere). For a review of WHO's Smallpox and its Eradication see Nature 332, 755 (1988). 